\title{
Developing Self-Regulation by Using Reflective Support in a Video-Digital Microteaching Environment
}

\author{
Zehavit Kohen and Bracha Kramarski \\ School of Education, Bar-Ilan University, Ramat-Gan 52900, Israel \\ Correspondence should be addressed to Zehavit Kohen, zehavit.kohen@biu.ac.il \\ Received 11 December 2011; Revised 20 March 2012; Accepted 13 April 2012 \\ Academic Editor: Mariel F. Musso
}

Copyright ( $) 2012$ Z. Kohen and B. Kramarski. This is an open access article distributed under the Creative Commons Attribution License, which permits unrestricted use, distribution, and reproduction in any medium, provided the original work is properly cited.

\begin{abstract}
Recent research efforts have established that self-regulated learning (SRL) is necessary for teachers to attain successful professional development. Our study addresses two central questions: under what conditions in preservice teachers' education can SRL processes be enhanced to the optimum level, and how can we assess these processes? The participants of the study were ninetyseven preservice teachers, who were engaged in real-time teaching in a video-digital Microteaching environment. Each participant was randomly assigned to one of two groups: reflective support (RS) for SRL or no support (NS) for SRL. Participants in the RS group were explicitly exposed to SRL aspects and were directed to address these aspects in their reflective discussions of the teaching experience. The SRL process was measured as an online event during real-time teaching exercises, based on a coding scheme developed for this study to identify and assess the SRL skills by two major aspects: metacognition (planning, information management, monitoring, debugging, and evaluating) and motivation (interest and value, self-efficacy, and teaching anxiety). Results indicate that the RS group outperformed the NS group in all SRL measures. Implications for reflective support for SRL and event measures of real-time observations of preservice teachers' SRL are discussed.
\end{abstract}

\section{Introduction}

The role of self-regulated learning (SRL) in education has drawn much attention recently to teachers' training programs, in light of findings that learners lack the knowledge and skills needed to effectively manage their learning (e.g., [1]). Research on SRL has focused on two central questions: how do students become masters of their own learning process? and how can this process be evaluated? [2, 3].

SRL refers to a cyclical and recursive process that involves three aspects: cognition, metacognition, and motivation [37]. Cognition refers to simple strategies, problem solving, and critical thinking; metacognition refers to the ability to understand and monitor cognitive skills; motivation refers to learners' interest level and the value they place on the task, as well as their beliefs and emotions regarding their capacity to learn. All of these aspects manifest themselves in a learning context (i.e., tasks), behaviors (i.e., time management), and learning conditions (i.e., group discussion).
There is empirical evidence (e.g., $[5,6]$ ) that the role of metacognition is particularly important for the learning process. Metacognition allows individuals to plan goals, activate prior knowledge and allocate learning resources; manage information with optimal efficiency; monitor current knowledge and skill levels; debug their work by improving their understanding and correcting mistakes; reflect learning performance against an acquired standard.

A growing body of literature highlights that metacognition develops during a person's life span (e.g., $[6,8]$ ), indicating that most adults have metacognitive knowledge (declarative, procedural, and conditional) and can plan accordingly (regulation of cognition). However, researchers argue that learners' cognitive and meta-cognitive skills are mediated by motivation and emotional aspects such as effort investment, self-efficacy, and task expectation, whereas negative feelings (i.e., anxiety) and low task expectations might prevent them from being engaged in the learning activity. Consequently, it is suggested that motivation is a key 
aspect that triggers the SRL cycle, emphasizing that the will (i.e., motivation) is the prerequisite for attaining the skill (metacognition) $[3,5,6,9,10]$.

The importance of SRL in the education system has set new goals for teacher training concerning the professional growth of preservice teachers [1]. Educators and researchers argue that teachers' ability to cultivate learners who are self-regulated during learning is tied to teachers' own selfregulation. If teachers are incapable of self-regulating their own learning, it will be difficult for them to instill these skills in their students [2, 11-14].

Research has indicated that SRL skills are not necessarily acquired spontaneously. Many students of all ages do not regulate themselves sufficiently, and even good learners may experience trouble regulating learning in unfamiliar domains or challenging circumstances $[2,3,15,16]$. Therefore, these skills should be developed and honed in settings that provide learners with opportunities to control their own learning $[10,16,17]$.

1.1. Training Preservice Teachers in SRL Skills. Teaching is a complex process for preservice teachers. Merely knowing the subject matter and pedagogical strategies, or how to manipulate a learning environment, is not the same as knowing how, when and why to use them [2]. A good teaching process includes understanding the material (i.e., knowing the subject matter and pedagogical strategies); identifying relevant topics for teaching (e.g., taking students' prior knowledge into account); selecting appropriate tools and environments (e.g., computer-learning environment); planning materials and strategies; reflecting on decisions and actions to evaluate goals, processes, and effort. This requires preservice teachers to use SRL skills from two perspectivesas learners (i.e., to acquire teaching skills) and as teachers (i.e., implement these skills in real-time teaching) $[11,18]$.

A review of current research on SRL training programs has shown that the more explicit the application and utility of SRL skills are, the more likely it is that teachers will implement SRL skills in both perspectives. Furthermore, SRL training should be part of the setting (i.e., the subject matter and learning environment) where the SRL process takes place. Otherwise, teachers have difficulty integrating the SRL skills into their learning and teaching [6, 15, 19-21].

Underpinning these demands, it is suggested that teachers' training programs should promote SRL skills by providing support for learning these skills explicitly and implementing them in their own teaching.

1.2. Reflective Support for Preservice Teachers'SRL. Reflection is defined as observing one's own thoughts, perceptions, actions, and achievements. Reflection is an important aspect in the self-regulation process (e.g., $[5,10]$ ) and is a central goal of teacher training; it helps teachers understand their own actions and learn from their experiences (e.g., [22, 23]). However, research indicates that teachers tend to use reflection in a descriptive, technical way by looking at what happened, without critical consideration of why or considering its implications. Therefore, researchers have suggested that systematic training programs with reflective aspects might be an appropriate framework for supporting critical reflection $[2,11,16,24-26]$.

Several methods and environments can be used to facilitate reflection in preservice teachers: verbal self-questioning (e.g., [2, 11, 16, 26]), inscribed portfolios to reflect on their development as teachers and help set future learning objectives (e.g., [27]), and a video-digital Microteaching environment based on recordings of lessons designed and presented by preservice teachers to their peers, followed by reflective discussion with the peers regarding the teaching performance (e.g., $[28,29])$. Reflection is particularly difficult in the Microteaching environment for preservice teachers, as they must take on the roles of teacher, student, classmate, and peer/friend, all within one task [28, 30].

Therefore, researchers have recommended scaffolding reflection, which assists the interaction between peers in the reflective process [31]. One of the common ways of scaffolding is reflective prompts, which is defined as an external stimulus that evokes strategy use with the objective of enhancing learning. Overall, research supports reflective prompting as a catalyst to foster the use of self-regulation strategies [32, 33]. Using reflection prompts helps learners focus on their own thoughts, processes, and activities while interacting with materials and peer interactions $[2,11,16$, 19, 34-36]. There are two types of reflection prompts: generic prompts that remind learners to "stop and think about" various aspects of the learning process without directing them towards specific evaluation criteria, and directed prompts that instruct the learners to reflect on specific SRL components [19, 34-36].

1.3. Assessing SRL Skills. There has been a great deal of discussion recently regarding methods for assessing SRL skills [3, 9, 37-40]. Previous studies focused on examining SRL using aptitude measures (also called offline measures), based on relatively stable traits that predict future behavior, usually via self-report questionnaires designed to aggregate self-regulatory responses (e.g., [41-43]). However, SRL intrinsically involves a dynamic feedback loop, in real time and within authentic settings, that require learners to respond to online changes in SRL as a function of both their skill (i.e., strategies use) and will (i.e., motivation). Therefore, there is an increasing concern regarding the quality of data from self-report measures of SRL processes (e.g., MSLQ: [41]). These measures are based on students' often inaccurate perceptions of their own self-regulatory processes $[3,39,44]$.

Researchers suggest that instead of relying on self-report measures, measuring SRL online in a series of events has the advantage of both being more consistent with SRL theory and providing more accurate data on how learners monitor and control their cognition, motivation, and behavior in a given setting $[3,9,15,44]$.

The Microteaching environment provides comprehensive data about teachers' SRL, since it enables one to view SRL behaviors and also to analyze processes in a dynamic social setting. However, the subject takes on the roles of teacher, student, classmate, and peer/friend, all within one task [30].

However, since analysis is time intensive, the main challenge in working with this type of data is to draw a valid 
inference that relates implicit online cognitive processes to individual events. Additionally, although online data collection is relatively simple, it is far more difficult to create a reliable scoring rubric or to develop online coding schemes that accurately reflect the breadth and depth of SRL in teaching [15]. To date, there have been few attempts at online study of preservice teachers' SRL during teaching [16].

Based on current recommendations for efficient SRL training, and taking the crucial role of reflection into consideration $[5,6,20,21,45]$, the first goal of this study was to investigate the effects of explicit reflective support for SRL in a video-digital Microteaching environment on preservice teachers' SRL. The second goal of this study was to explore methods of assessing SRL in real time.

In this study, we propose to examine preservice teachers' SRL online processes in a Microteaching exercise, with particular emphasis on measuring dynamic self-regulatory events [3]. This study addresses two questions: (1) what are the effects of reflective support (RS) in a video-digital Microteaching environment on the development of SRL skills? and (2) how can SRL be measured as an online event during a real-time teaching exercise?

\section{Method}

2.1. Participants. Participants included ninety-seven preservice high-school teachers enrolled in a required undergraduate course in "Microteaching." The participants were randomly assigned to two experimental groups: reflective support (RS) and no support (NS) for SRL. Pretest comparison of the two groups showed no significant differences in gender, age, or teaching experience. A quantitative comparison measuring the participants' pedagogical knowledge in lesson design and self-report SRL questionnaire (MAI: [46]) also revealed no differences between the groups, respectively, $(F(3,91)=0.718 ; P>0.05 ; F(6,90)=0.885 ; P>0.05)$.

The study commenced at the start of the academic semester and comprised twelve weekly pedagogical workshops, each two hours in length (twenty-four hours of training in total).

2.2. Training: RS versus NS. Both groups (RS and NS) of preservice teachers were assigned real-time teaching exercises in a video-digital Microteaching classroom simulation, approximately fifteen minutes in length. The teaching exercise was selected by the preservice teacher and related to one of the required topics in the curriculum as mandated by the Israeli Ministry of Education. The exercise was recorded on video and immediately followed by an evaluation by the participant's peers and the instructor in a reflective discussion.

The first two workshops exposed the participants to theoretical pedagogical frameworks (e.g., $[47,48]$ ) which emphasize the necessary knowledge for performing pedagogical tasks. These theories were explicitly discussed as well as implemented in pedagogical tasks, such as an analysis of a lesson design or video lessons specific events.

Then, the reflective discussions for evaluating the teaching exercise during the pedagogical workshops were directed by generic prompts to "think about" [34] pedagogical issues (e.g., the structure of the lesson; student-teacher interaction), teaching skills (e.g., asking questions), awareness of body language, and correct use of the board. In addition to the generic prompting that was provided to both groups, the reflective support (RS) group was given explicit instruction to include SRL in its discussion.

2.3. RS for $S R L$. The RS preservice teachers were exposed to SRL theory based on Schraw et al. [6] and Zimmerman [45]. The discussion included theoretical and research findings that dealt with both the meta-cognitive aspect of the SRL process (planning, information management, monitoring, debugging, and evaluation) and the motivation aspect of SRL (interest and value, self-efficacy, and teaching anxiety). To help the participants internalize the use of SRL process, they were given pedagogical exercises that focused explicitly on the use of SRL skills, such as analyzing a video-recorded lesson while paying specific attention to the teacher's SRL in at different points in the lesson.

The importance of explicit reflection in every phase of the SRL process was emphasized. Consequently, the RS group was told to direct their reflective discussions in the pedagogical workshops by focusing on clear descriptions of what happened and why. The evaluation utilized flashcards that included references to the various components of SRL from the meta-cognitive and motivation aspects, such as: "The student put thought into the planning of the lesson"(planning component); "The student occasionally asked himself whether he was responding appropriately" (monitoring component); "At the end of the lesson, the student evaluated his achievement of the lesson's goals" (evaluation component); "It was important to the student to succeed in the teaching task" (interest and value of the teaching task component); "The student believed in his ability to succeed in the teaching task" (self-efficacy component); "The student was focused and his thoughts were clear" (teaching anxiety component). Table 1 summarizes the experimental design, by group.

2.4. Assessment Measures. We measured SRL skills in terms of online events during a fifteen-minute teaching exercise in a Microteaching environment. Using theories proposed by Schraw et al. [6] and Pintrich [5], we developed a coding scheme to identify and assess skills in both the meta-cognitive aspect (planning, information management, monitoring, debugging, and evaluating) and the motivation aspect (interest and value, self-efficacy, and teaching anxiety) of SRL. In contrast to the study of these aspects of SRL that has been generally done offline (i.e., questionnaires), our coding scheme was implemented on the video-digitalrecorded observations of real-time teaching exercises.

The digital observations were transcribed and assessed in two steps. Three expert judges analyzed ten videorecorded teaching exercises (the lesson taught in the exercises differed according to the subject's field of expertise) that had been taken from previous Microteaching courses. Judges independently analyzed the lessons by first dividing the content into events (i.e., meaningful utterances) and then categorizing each event according to the SRL aspects defined 
TABLE 1: Layout of experimental design, by group (reflective support/no support for SRL).

\begin{tabular}{lll}
\hline & Description & $\begin{array}{c}\text { Reflective } \\
\text { support for SRL } \\
\text { (RS) }\end{array}$ \\
\hline $\begin{array}{l}\text { Active engagement-teaching } \\
\text { experience in real time }\end{array}$ & $\begin{array}{l}\text { Fifteen-minute teaching exercise, recorded on video-digital film } \\
\text { Exposure to theoretical pedagogical frameworks; practicing this } \\
\text { knowledge via pedagogical exercises } \\
\text { Evaluation of the teaching experience through reflective discussion } \\
\text { directed by generic prompts to foster teaching skills }\end{array}$ & $\sqrt{ }$ \\
\hline \multirow{2}{*}{$\begin{array}{l}\text { Explicit instruction-fostering } \\
\text { SRL skills }\end{array}$} & $\begin{array}{l}\text { Explicit instruction of the SRL process; practicing SRL skills via } \\
\text { pedagogical exercises }\end{array}$ \\
& $\begin{array}{l}\text { Directed reflective support (flashcards) during evaluation of the } \\
\text { teaching experience to foster SRL skills by discussion of what and } \\
\text { why these skills are important }\end{array}$ & $\sqrt{ }$ \\
\hline
\end{tabular}

TABLE 2: Mean scores, standard deviations, and Cohen's $d$ scores for SRL (metacognition and motivation) by experimental group.

\begin{tabular}{|c|c|c|c|c|c|c|c|}
\hline & & \multicolumn{4}{|c|}{ Support for SRL } & \multirow[b]{3}{*}{$F(1,95)$} & \multirow[b]{3}{*}{$d$} \\
\hline & & \multicolumn{2}{|c|}{ Reflective support (RS) $n=47$} & \multicolumn{2}{|c|}{ No support (NS) $n=50$} & & \\
\hline & & $M$ & $\mathrm{SD}$ & M & $\mathrm{SD}$ & & \\
\hline \multirow{5}{*}{ Metacognition } & Planning & 2.50 & .50 & 1.47 & .69 & $71.44^{* * *}$ & 1.51 \\
\hline & $\begin{array}{l}\text { Information } \\
\text { management }\end{array}$ & 2.53 & .40 & 1.84 & .76 & $30.17^{* * *}$ & 0.90 \\
\hline & Monitoring & 2.36 & .44 & 1.44 & .83 & $44.93^{* * *}$ & 1.10 \\
\hline & Debugging & 2.37 & .77 & 1.66 & .86 & $18.24^{* * *}$ & 0.83 \\
\hline & Evaluating & 2.46 & .62 & .81 & .68 & $152.88^{* * *}$ & 2.41 \\
\hline \multirow{3}{*}{ Motivation } & Interest and value & 2.77 & .48 & 1.56 & .97 & $35.23^{* * *}$ & 1.24 \\
\hline & Self-efficacy & 2.65 & .50 & 1.82 & .94 & $16.65^{* * *}$ & 0.89 \\
\hline & Teaching anxiety & 2.50 & .44 & 1.65 & .86 & $17.51^{* * *}$ & 0.99 \\
\hline
\end{tabular}

$* * * P<.0001$.

Note 1: component scores range from 0 to 3.

Note 2: high score in the teaching anxiety variable represents an absence of anxiety.

Note 3: $d$ was calculated as the ratio between the difference between the two groups and the average standard deviation of the NS group.

by Schraw and Dennison [46] into categories for regulation of cognition and Pintrich et al. [41] categories for motivation. For example, events indicating that the preservice teacher occasionally asked himself/herself whether he/she was clear enough to ensure the students' understanding (e.g., when a participant stopped the lesson and said "I must give an introduction" because he/she saw that the students had misunderstood what he had taught) were coded as the component of monitoring (Metacognition aspect of SRL); or events in which the preservice teacher showed confidence (e.g., when a participant asked "Are you ready to practice by yourselves?" and the class did not respond, he was not thrown off balance and instead countered humorously, "You don't know?...") were classified as self-efficacy (motivation aspect of SRL) (See the appendix presents the coding scheme and additional examples).

After consolidating components and agreement on events, the judges classified the scores as high (3), medium (2), low (1), or absent (0). Final scores ranged from 0 to 24 (score $\times 8$ components). An event was scored as high (3) when the preservice teacher showed explicit use of SRL with consideration (e.g., explanations) of "why" the preservice teacher used this event; an event was scored as medium (2) when the preservice teacher showed explicit use of SRL without additional consideration; an event was scored as low (1) when the preservice teacher showed implicit use of SRL during the event.

Interjudge reliability was calculated between the three expert judges who evaluated six additional video-recorded teaching exercises by scoring each SRL event which appeared in the lessons according to the coding scheme. This process yielded high interjudge reliability $(r=0.89)$. See the appendix presents the SRL coding scheme, a description of each component and examples of event scoring (i.e., meaningful statement or behavior) as occurred during the real-time teaching experience.

\section{Results}

A one-way MANOVA followed by ANOVAs on the Metacognition and motivation variables indicated significant differences between the two groups (RS and NS) in both 


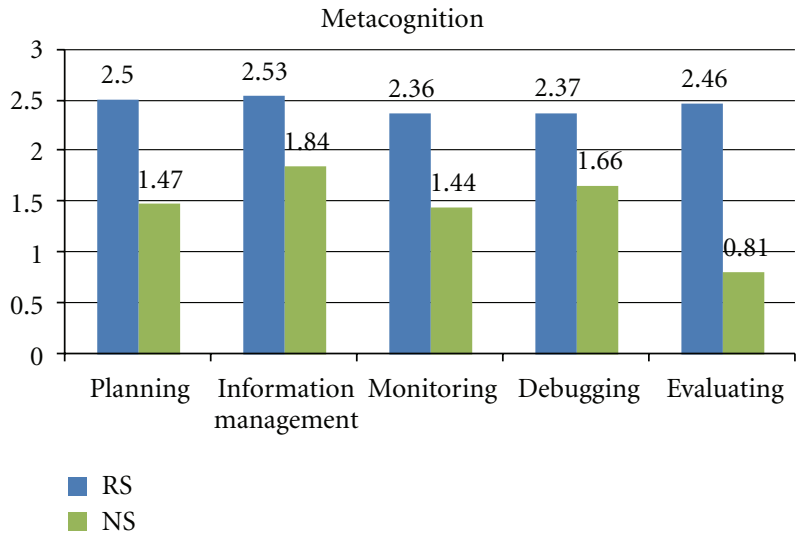

Figure 1: Metacognition level according to reflective support/no support for SRL.

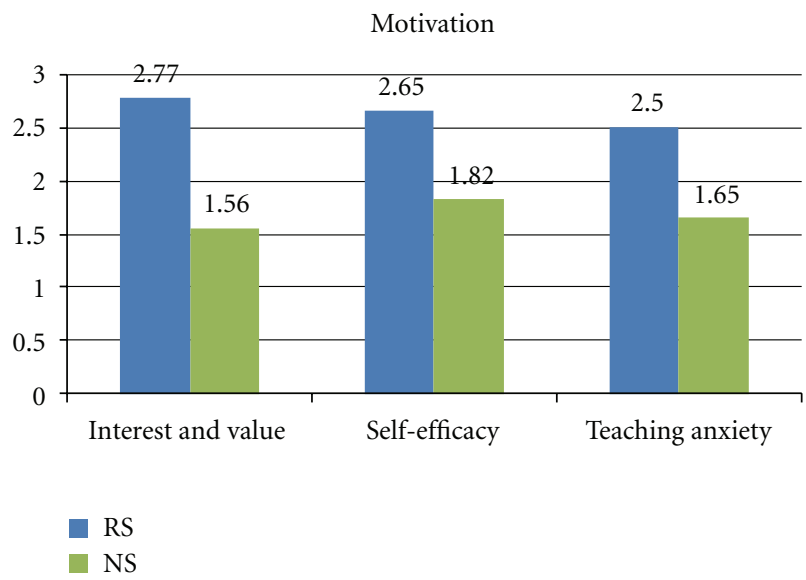

Figure 2: Motivation level according to reflective support/no support for SRL.

Metacognition (see Table 2 and Figure 1): $F(5,91)=38.470$, $P<0.0001, \eta^{2}=0.679$, and motivation (see Table 2 and Figure 2): $F(3,93)=21.236, P<0.0001, \eta^{2}=0.407$.

According to the mean scores displayed in Table 2 and Figures 1 and 2 and the effect sizes between the groups, significant differences were found between the groups. The group who received reflective support for SRL (the RS group) displayed higher levels of meta-cognitive skills, which were evident in (1) clearer (i.e., structured) lesson plans; (2) better management of information; (3) increased use of self-judgment during the teaching exercise; (4) correct handling of errors arising during the teaching exercise; (5) increased attention to content taught and lesson goals achieved. Findings indicated particularly large differences between the groups on planning $(d=1.51)$, monitoring $(d=1.10)$, and evaluation $(d=2.41)$. In contrast, the NS group did not often engage in evaluation processes, which are crucial for the reflection phase in the SRL cyclical model $[3,10]$. As for the motivation components, the RS group displayed greater interest and value of teaching $(d=2.77)$, higher self-efficacy $(d=2.65)$, and less teaching anxiety $(d=$ $2.50)$ than the NS group ( $d=1.56 ; 1.82 ; 1.65$, respectively).

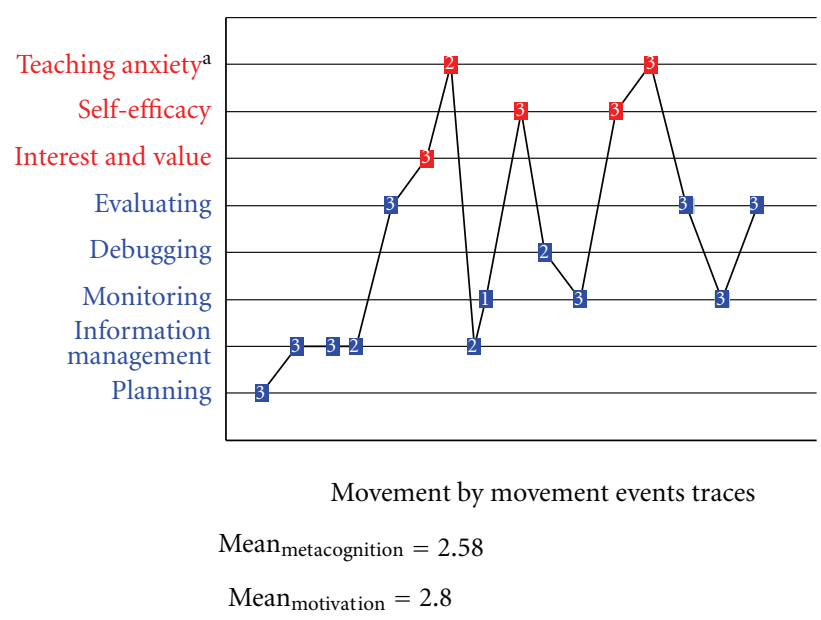

Figure 3: SRL events traces of the participant "A" from the RS group.

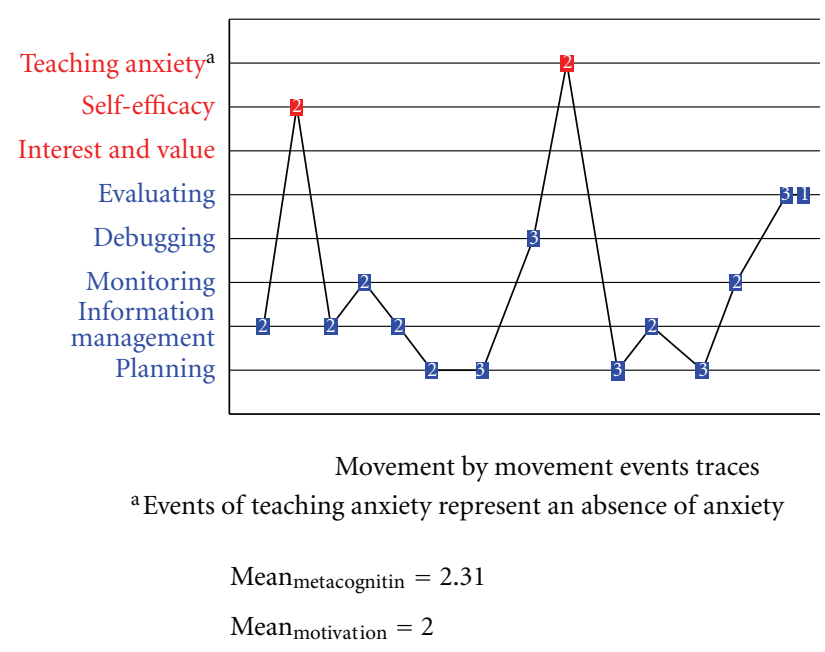

FIgURE 4: SRL events traces of the participant "B" from the NS group.

To better understand the development of SRL in both groups, two graphs of SRL movement-by-movement events traces illustrate the measurement of SRL throughout the teaching exercise in the Microteaching environment (fifteen minutes). These SRL traces were selected randomly from real-time teaching exercises using one preservice student from each experimental group (see Figures 3 and 4).

As seen in these figures, the participant from the RS group demonstrated more events of SRL (17 events) than the participant from the NS group (15 events). And it is worth noting that the participant from the RS group mentioned the motivation aspects ( 5 events), whereas the participant from the NS group practically ignored them (2 events).

The graphs also highlight different patterns in the SRL event traces. While the participant from the RS group alternated between different aspects of SRL, the participant from the NS group mainly focused on two components of the meta-cognitive aspect (planning and information management). 


\section{Discussion}

Current research in the field of SRL deals with two central issues: the means by which learners control their own learning process and how this process may be assessed [2, 3]. This study addresses these issues, specifically the role of reflective support of SRL in preservice teachers' professional training.

Our findings indicate that although preservice teachers from both groups were exposed to reflective discussion about real-time teaching experiences, these had different effects on SRL. The group that received reflective support (RS) for SRL displayed higher levels of SRL skills during their teaching exercise than the group that did not receive support. The SRL skills were manifested in both the meta-cognitive aspect (planning, information management, monitoring, debugging and evaluating) and the motivation aspect (interest and value, self-efficacy, and teaching anxiety).

These findings can be explained by the different instructions given to each group. The RS group was guided specifically to pay attention to the SRL aspects (Metacognition and motivation) and was directed to use flashcards throughout the reflective process in order to think about and reflect on (what happened and why) the different aspects of SRL. The NS group was directed to use generic reflection, with tacit and implicit instructions such as "think about" [34], which may not have helped them fully utilize the reflective discussion to develop their SRL. These findings support Schön's [49] conclusion that using knowledge in tacit and implicit situations is especially problematic for inexperienced preservice teachers. In contrast, the directed discussion with flashcards enabled the preservice teachers to progress through the SRL aspects (Metacognition and motivation) in the teaching exercise, which may have helped them reflect on learning and teaching from different perspectives. Our findings also support previous studies which showed that explicit support of SRL is necessary for the activation of SRL processes in any learning environment $[2,6,19,21,50,51]$.

In addition, we found that explicit SRL support strengthened the motivation (interest, value of the tasks and selfefficacy) of the RS group. Our findings support the theory that motivation is an inherent part of the SRL cycle, thus enabling the use of Metacognition (e.g., [5, 10, 15]). This is important because the motivation aspect of SRL has been given less attention by researchers than the metacognitive aspect (e.g., [15]).

Current research on SRL highlights the importance of measuring SRL as an online event (e.g., [3]). Event measures are wellsuited for making causal inferences about online changes in SRL in an authentic setting. They offer researchers not only a sensitive measure of SRL, but also a measure of the efficacy of various interventions geared towards encouraging learners to use SRL skills $[3,52]$. Our study focused on the observation of teaching experiences. Until now, little research in the SRL field has been done using real-time observations of preservice teachers' SRL behaviors. For a comprehensive understanding of these behaviors, we developed a coding scheme designed to assess SRL events during the analysis of video-digital-recorded teaching exercises.
However, the coding scheme enabled to analyze SRL as it appeared (visible) in the video-recorded lessons' statements and behaviors. We suggested that a further research add qualitative data to illustrate the SRL processes. In particular, the data can be collected on preservice teachers' internal processes as self-reflections by interviewing the teachers on their thinking and during their lesson.

4.1. Practical Implications, Future Research, and Limitations. Our study makes an important contribution to the training of preservice teachers, with a focus on increasing their SRL skills. We recommend the use of critical reflective discussion, which guides learners in understanding why things happened while observing what happened, as a training method to support the learning process and professional development of preservice teachers. In our study, we found that using directed prompts, such as flashcards referring to specific evaluation criteria, can help conduct a productive critical reflective discussion.

This study focuses on preservice teachers during their training. We recommend tracking these preservice teachers during their first year as inservice teachers to examine their future professional behavior as a function of the type of reflective support they received during their training period.

Our goal was to examine the effects of reflection support on SRL events. Our online measurements provided us with rich data about aspects of the SRL process (Metacognition and motivation). However, the study was conducted in laboratory conditions using a video-digital Microteaching environment. To strengthen the validity of our measure, we recommend observing the SRL process of beginning inservice teachers during an active experience in the field, using the same coding scheme that we developed. We also suggest that future studies implement other event measures with time-series analysis techniques to observe SRL behavior [3]. Our study focused only on the effects of RS on SRL. We suggest for further research to examine the effects of explicit RS on preservice teachers' ability to transfer their SRL skills to different types of knowledge, for example, use of pedagogical content knowledge or subject content knowledge, and examine its impact on the academic performance of teachers working in various disciplines, school types, and cultures with a wide range of personal characteristics. In addition, the data gathered for this study was only in 15-minute segments; we cannot therefore draw conclusions regarding the pattern of all SRL behaviors in other teaching settings. For further research, we suggest a long-term study (e.g., at 6 months and 12 months after SRL training), including evaluations of both kinds (aptitude and events). Such a study should use complementary measures to assess aptitudes (questionnaires) and events, such as thinking aloud, observations, log-files, and forum discussions (e.g., [53]). This may shed further light on the effects of explicit, critical reflection support on other internalSRL events which could not be observed with our type of measure.

Our study implemented explicit reflective support for developing SRL with preservice teachers. In our opinion, the study of reflective support as a springboard for fostering SRL should remain a focus point for future research. Further 


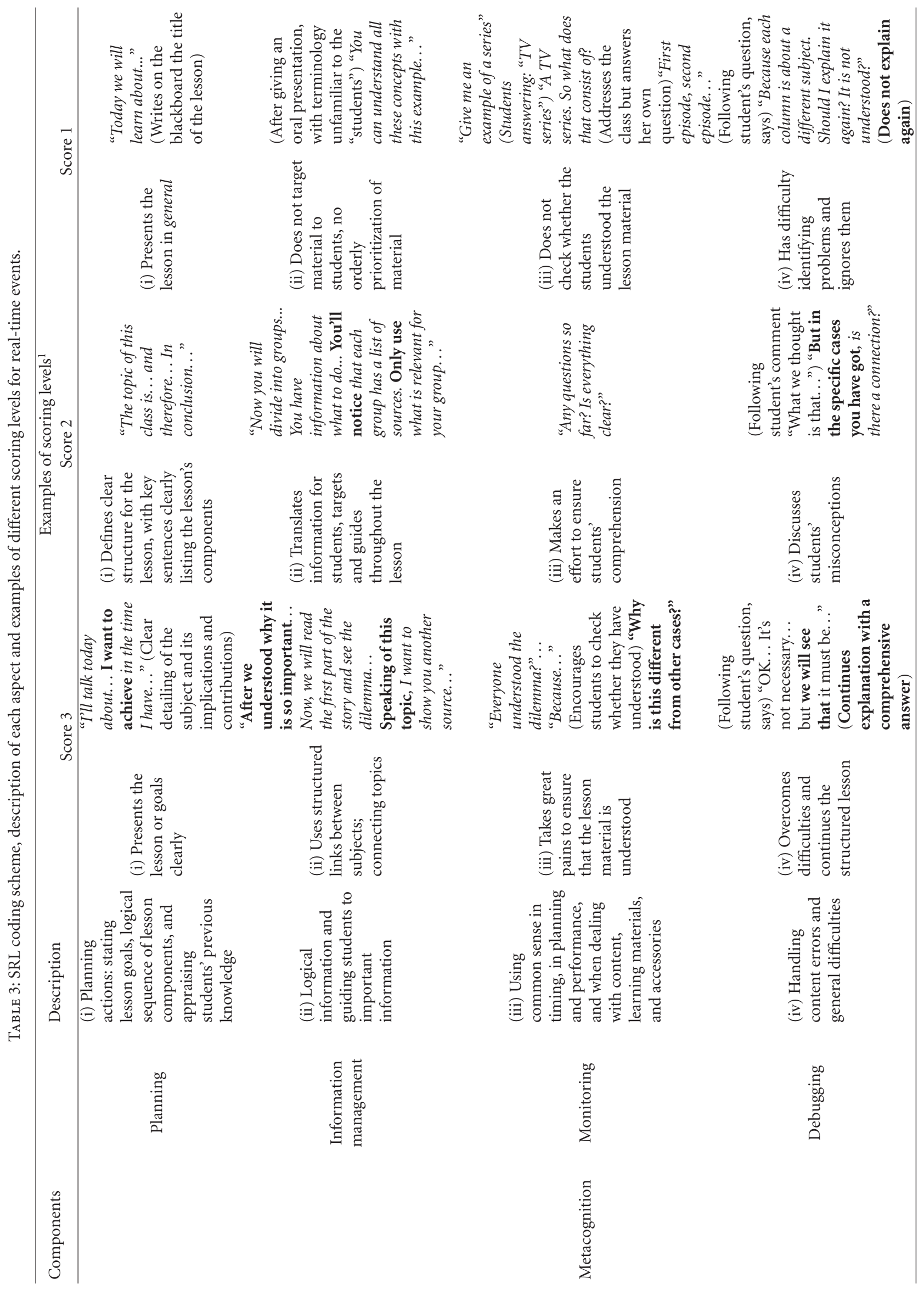




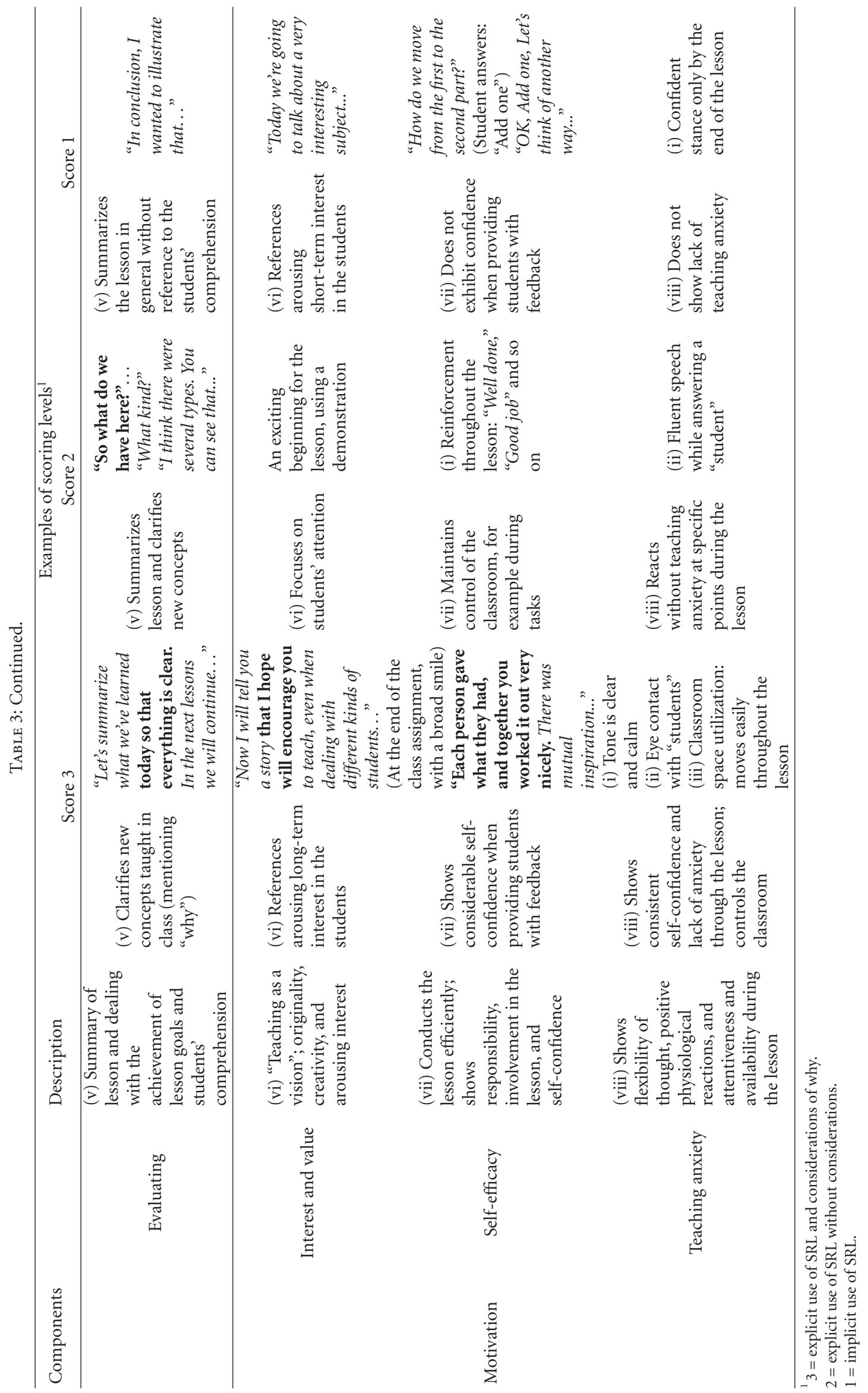


studies may devise and apply other models for supporting SRL development in preservice and in-service teachers in different learning environments.

In summary, this study offers a practical intervention and a valid and reliable tool for assessing teachers' SRL, with the goal of enhancing such competencies not only for teachers but also for students.

\section{Appendix}

For more details see Table 3 .

\section{References}

[1] National Council for Accreditation of Teacher Education, Professional Standards for the Accreditation of Schools, Colleges, and Departments of Education, National Council for Accreditation of Teacher Education, Washington, DC, USA, 2002.

[2] B. Kramarski and T. Michalsky, "Investigating preservice teachers' professional growth in self-regulated learning environments," Journal of Educational Psychology, vol. 101, no. 1, pp. 161-175, 2009.

[3] B. J. Zimmerman, "Investigating self-regulation and motivation: historical background, methodological developments, and future prospects," American Educational Research Journal, vol. 45, no. 1, pp. 166-183, 2008.

[4] D. L. Butler and S. C. Cartier, "Multiple complementary methods for understanding self-regulated learning as situated in context," in Proceedings of the AERA Annual Conference, Montreal, Canada, 2005.

[5] P. R. Pintrich, "The role of goal orientation in self-regulated learning," in Handbook of Self-Regulation, M. Boekaerts and P. R. Pintrich, Eds., pp. 13-39, Academic Press, San Diego, Calif, USA, 2000.

[6] G. Schraw, K. J. Crippen, and K. Hartley, "Promoting selfregulation in science education: metacognition as part of a broader perspective on learning," Research in Science Education, vol. 36, no. 1-2, pp. 111-139, 2006.

[7] P. H. Winne and A. F. Hadwin, "Studying as self-regulated learning," in Metacognition in Educational Theory and Practice, D. J. Hacker, J. Dunlosky, and A. Graesser, Eds., pp. 277-304, Lawrence Erlbaum Associates, Hillsdale, NJ, USA, 1998.

[8] M. V. J. Veenman, B. H. A. M. Van Hout-Wolters, and P. Afflerbach, "Metacognition and learning: conceptual and methodological considerations," Metacognition and Learning, vol. 1, no. 1, pp. 3-14, 2006.

[9] M. Boekaerts and E. Cascallar, "How far have we moved toward the integration of theory and practice in selfregulation?" Educational Psychology Review, vol. 18, no. 3, pp. 199-210, 2006.

[10] B. J. Zimmerman, "Self-efficacy: an essential motive to learn," Contemporary Educational Psychology, vol. 25, no. 1, pp. 8291, 2000.

[11] B. Kramarski and T. Michalsky, "Preparing preservice teachers for self-regulated learning in the context of technological pedagogical content knowledge," Learning and Instruction, vol. 20, no. 5, pp. 434-447, 2010.

[12] N. E. Perry, L. Phillips, and L. R. Hutchinson, "Mentoring student teachers to support self-regulated learning," Elementary School Journal, vol. 106, no. 3, pp. 237-254, 2006.
[13] J. Randi and L. Corno, "Teacher innovations in self-regulated learning," in Handbook of Self-Regulation, M. Boekaerts, P. Pintrich, and M. Zeidner, Eds., pp. 651-685, Academic Press, Orlando, Fla, USA, 2000.

[14] A. Zohar, Higher Order Thinking in Science Classrooms: Students' Learning and Teacher' Professional Development, Kluwer Academic, Dodrecht, The Netherlands, 2004.

[15] M. Boekaerts and L. Corno, "Self-regulation in the classroom: a perspective on assessment and intervention," Applied Psychology, vol. 54, no. 2, pp. 199-231, 2005.

[16] B. Kramarski and T. Michalsky, "Preparing preservice teachers for self-regulated learning in the context of technological pedagogical content knowledge," Learning and Instruction, vol. 20, no. 5, pp. 434-447, 2010.

[17] B. Kramarski and Z. R. Mevarech, "Enhancing mathematical reasoning in the classroom: the effects of cooperative learning and metacognitive training," American Educational Research Journal, vol. 40, no. 1, pp. 281-310, 2003.

[18] R. T. Putnam and H. Borko, "What do new views of knowledge and thinking have to say about research on teacher learning?" Educational Research, vol. 29, no. 1, pp. 4-15, 2000.

[19] M. Bannert, "Metacognitive prompting: design and effects when learning with hypermedia," in Proceedings of the AERA Annual Conference, 2008.

[20] M. Boekaerts, "Self-regulated learning: where we are today," International Journal of Educational Research, vol. 31, no. 6, pp. 445-457, 1999.

[21] M. V. J. Veenman, B. H. A. M. Van Hout-Wolters, and P. Afflerbach, "Metacognition and learning: conceptual and methodological considerations," Metacognition and Learning, vol. 1, no. 1, pp. 3-14, 2006.

[22] D. A. Schön, The Reflective Practitioner: How Professionals Think in Action, Basic Books, New York, NY, USA, 1983.

[23] K. Zeichner, "Changing directions in the practicum: looking ahead to the 1990's," Journal of Education for Teaching, vol. 16, no. 2, pp. 105-131, 1990.

[24] D. L. Butler, H. N. Lauscher, S. Jarvis-Selinger, and B. Beckingham, "Collaboration and self-regulation in teachers" professional development," Teaching and Teacher Education, vol. 20, no. 5, pp. 435-455, 2004.

[25] L. Corno and J. Randi, "A design theory for classroom instruction," in Instructional-Design Theories and Models: A New Paradigm of Instructional Theory, C. M. Reigeluth, Ed., vol. 2, chapter 13, Lawrence Erlbaum, Mahwah, NJ, USA, 1999.

[26] K. Green, "No novice teacher left behind: guiding novice teachers to improve decision-making through structured questioning," Perspectives on Urban Education, vol. 4, no. 1, pp. $1-9,2006$.

[27] R. Tanner, D. Longayroux, D. Beijaard, and Verloop N., "Piloting portfolios: using portfolios in pre-service teacher education," ELT Journal, vol. 54, no. 1, pp. 20-30, 2000.

[28] D. Cruickshank, "Uses and benefits of reflective teaching," The Phi Delta Kappan, vol. 66, no. 10, pp. 704-706, 1985.

[29] D. S. McCurry, "Technology for critical pedagogy: beyond self-reflection with video," in Proceedings of the Society for Information Technology \& Teacher Education International Conference (SITE '00), vol. 1, no. 3, pp. 6-11, San Diego, Calif, USA, 2000.

[30] N. D. Bell, "Microteaching: what is it that is going on here?" Linguistics and Education, vol. 18, no. 1, pp. 24-40, 2007. 
[31] D. K. Meyer and J. C. Turner, "Using instructional discourse analysis to study the scaffolding of student self-regulation," Educational Psychologist, vol. 37, no. 1, pp. 17-25, 2002.

[32] R. Azevedo, J. G. Cromley, and D. Seibert, "Does adaptive scaffolding facilitate students' ability to regulate their learning with hypermedia?" Contemporary Educational Psychology, vol. 29, no. 3, pp. 344-370, 2004.

[33] D. F. Kauffman, R. Zhao, and Y. S. Yang, "Effects of online note taking formats and self-monitoring prompts on learning from online text: using technology to enhance self-regulated learning," Contemporary Educational Psychology, vol. 36, no. 4, pp. 313-322, 2011.

[34] E. A. Davis, "Prompting middle school science students for productive reflection: generic and directed prompts," Journal of the Learning Sciences, vol. 12, no. 1, pp. 91-142, 2003.

[35] D. F. Kauffman, X. Ge, K. Xie, and C. H. Chen, "Prompting in web-based environments: supporting self-monitoring and problem solving skills in college students," Journal of Educational Computing Research, vol. 38, no. 2, pp. 115-137, 2008.

[36] B. Kramarski and N. Mizrachi, "Online discussion and self-regulated learning: effects of instructional methods on mathematical literacy," Journal of Educational Research, vol. 99, no. 4, pp. 218-229, 2006.

[37] J. A. Greene and R. Azevedo, “The measurement of learners' self-regulated cognitive and metacognitive processes while using computer-based learning environments," Educational Psychologist, vol. 45, no. 4, pp. 203-209, 2010.

[38] G. Schraw, "Measuring self-regulation in computer-based learning environments," Educational Psychologist, vol. 45, no. 4, pp. 258-266, 2010.

[39] P. H. Winne and N. E. Perry, "Measuring self-regulated learning," in Handbook of Self-Regulation, M. Boekaerts, P. Pintrich, and M. Zeidner, Eds., pp. 531-566, Academic Press, Orlando, Fla, USA, 2000.

[40] P. H. Winne and J. C. Nesbit, "Supporting self-regulated learning with cognitive tools," in Handbook of Metacognition in Education, D. J. Hacker, J. Dunlosky, and A. C. Graesser, Eds., pp. 259-277, Routledge, New York, NY, USA, 2009.

[41] P. R. Pintrich, D. A. F. Smith, T. Garcia, and W. J. McKeachie, "Reliability and predictive validity of the Motivated Strategies for Learning Questionnaire (MSLQ)," Educational and Psychological Measurement, vol. 53, pp. 801-813, 1993.

[42] B. J. Zimmerman and M. Martinez-Pons, "Development of a structured interview for assessing students' use of selfregulated learning strategies," American Educational Research Journal, vol. 23, pp. 614-628, 1986.

[43] B. J. Zimmerman and M. Martinez Pons, "Construct validation of a strategy model of student self-regulated learning," Journal of Educational Psychology, vol. 80, no. 3, pp. 284-290, 1988.

[44] P. H. Winne and D. Jamieson-Noel, "Exploring students' calibration of self reports about study tactics and achievement," Contemporary Educational Psychology, vol. 27, pp. 551-572, 2002.

[45] B. J. Zimmerman, "Becoming a self-regulated learner: an overview," Theory into Practice, vol. 41, no. 2, pp. 64-70, 2002.

[46] G. Schraw and R. S. Dennison, "Assessing metacognitive awareness," Contemporary Educational Psychology, vol. 19, no. 4, pp. 460-475, 1994.

[47] D. L. Ball, "Content knowledge for teaching, what makes it special?" Journal of Teacher Education, vol. 59, no. 5, pp. 389407, 2008 .
[48] L. Shulman, "Those who understand: knowledge growth in teaching," Educational Researcher, vol. 15, no. 2, pp. 4-14, 1986.

[49] D. A. Schön, “The new scholarship requires a new epistemology," Change, vol. 27, pp. 26-34, 1995.

[50] H. J. Hartman, "Teaching metacognitively," in Metacognition in Learning and Instruction: Theory, Research and Practice, $\mathrm{H}$. J. Hartman, Ed., pp. 33-68, Kluwer, Boston, Mass, USA, 2001.

[51] B. Kramarski and M. Gutman, "How can self-regulated learning be supported in mathematical E-learning environments?" Journal of Computer Assisted Learning, vol. 22, no. 1, pp. 24-33, 2006.

[52] N. E. Perry, "Young Children's self-regulated learning and contexts that support it," Journal of Educational Psychology, vol. 90, no. 4, pp. 715-729, 1998.

[53] M. V. J. Veenman, "The assessment and instruction of selfregulation in computer-based environments: a discussion," Metacognition and Learning, vol. 2, no. 2-3, pp. 177-183, 2007. 


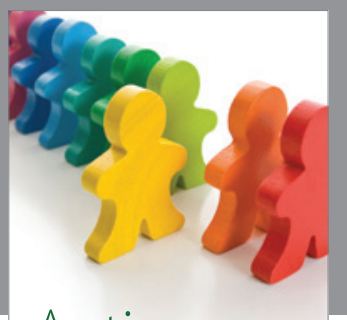

Autism

Research and Treatment
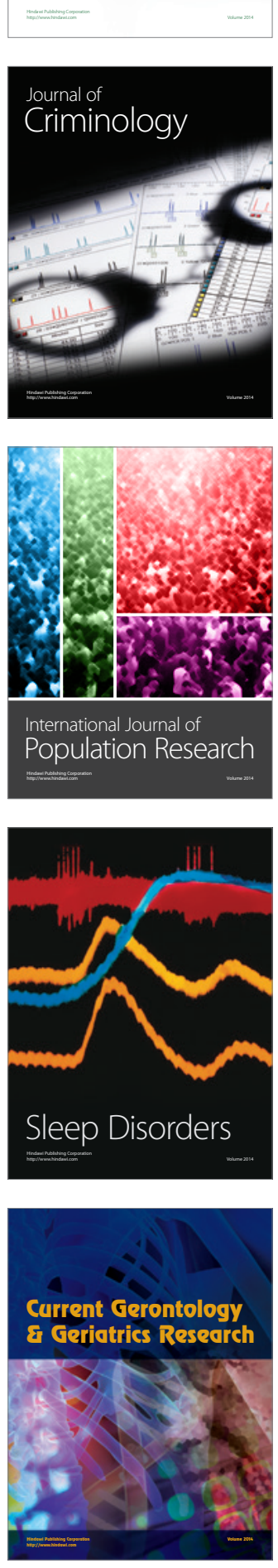
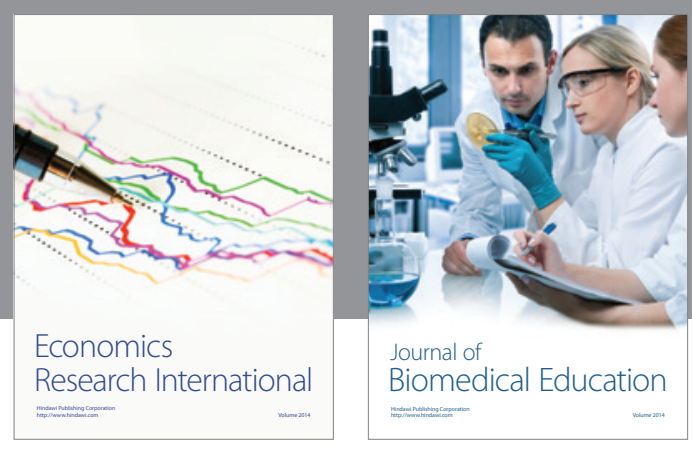

Journal of

Biomedical Education

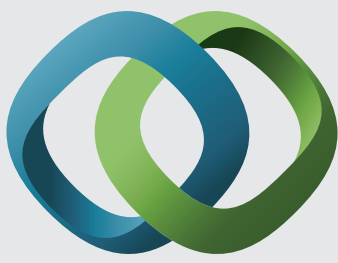

\section{Hindawi}

Submit your manuscripts at

http://www.hindawi.com
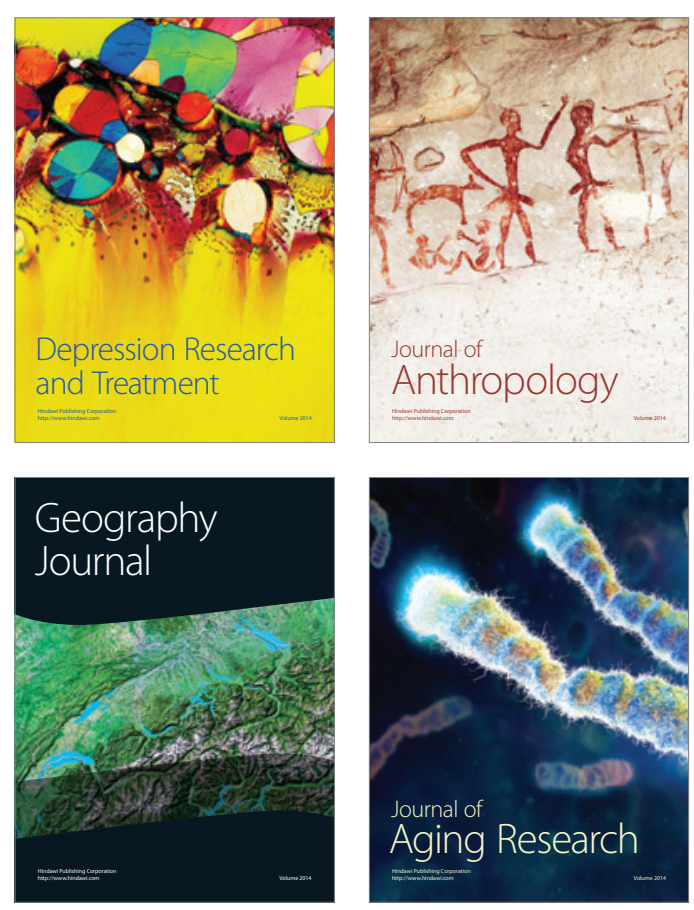

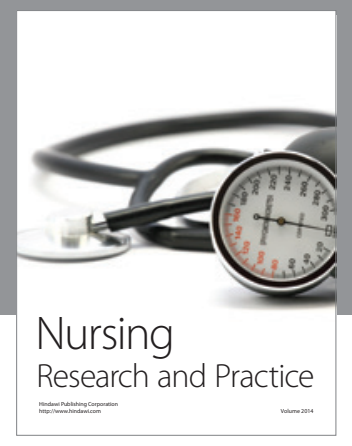

Nursing

Research and Practice

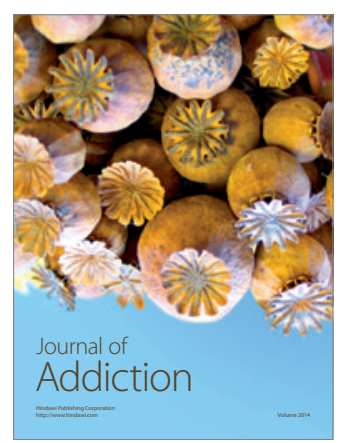

Child Development

Research

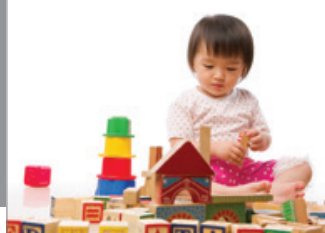

迥
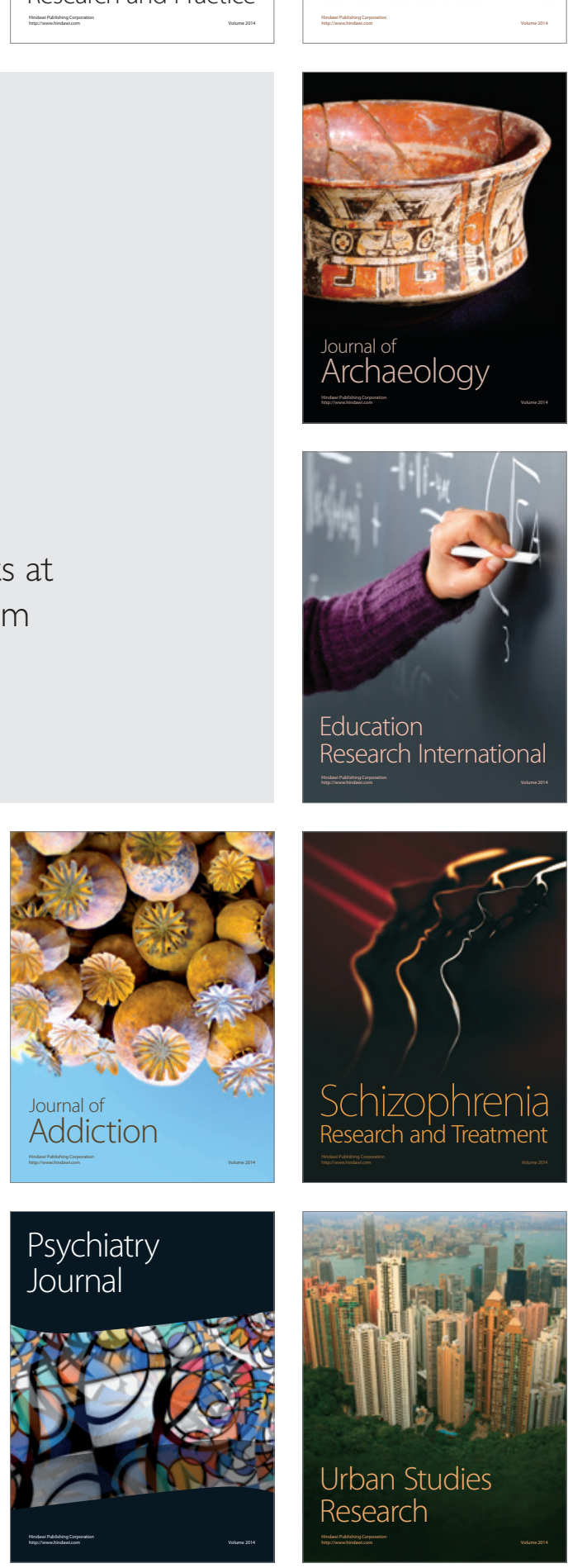